the Swiss Federal Research Station, all suggest that the dioxin precursors are not so nebulous. Rappe considers that chlorinated phenols and chlorinated diphenyl ethers are the main precursors in municipal incinerators. When these two groups of compounds are heated under laboratory conditions, Rappe has found that they produce isomers of chlorinated dioxins in similar proportions to those seen in commercial incinerators. Although Rappe forwarded his results to Dow, it appears either that they were not interested or that they chose to ignore his findings, for there are no analyses for these precursors in the Dow report.

The chromatographic separation techniques used by Dow to identify dioxin isomers are poor, according to Rappe, and their samples should be reanalysed using another method (see diagram on p619). In Rappe's opinion, Dow have overestimated the quantity of the dioxin isomer $2,3,7,8$-tetrachlorodibenzo-p-dioxin $(2,3,7,8$-TCDD) which would be present in the fly ash of municipal incinerators. This isomer is many times more toxic than any of the other chlorinated dioxin isomers studied so far, and Rappe says that it represents only $1-3 \%$ of the tetrachlorinated dioxin isomers in European incinerator fly ash. Dow, on the other hand, report that in some cases $2,3,7,8$-TCDD was the major tetrachlorinated isomer. Rappe suggests that this dramatic difference between his and Dow's results could be explained by the fact that Dow analysed samples from one of their own incinerators. Dow incinerates residue from the reactor used to make 2,4,5-trichlorophenol, the precursor of the herbicide 2,4,5-T. As the incineration of 2,4,5- trichlorophenol is known to produce $2,3,7,8-T C D D$, Rappe suggests that the chlorinated phenol may have already been present in the reactor.

Rappe and his colleagues have so far prepared and identified 31 of the 75 chlorinated dioxin isomers which are considered to be theoretically possible. Although Dow used a far fewer (and unstated) number in its study, they believe that they identified enough isomers to make the report valid. In addition, Bumb points out that another Dow scientist, Dr D E Townsend has verified the trace chemistries theory from thermodynamic principles. Bumb told Nature that
Townsend, in an unpublished report, finds a striking correlation between observed and predicted values for the dioxin isomers. Rappe disputes one of Townsend's assumptions (a constant ratio between dioxin isomers with different numbers of chlorine atoms): "consequently his basic theory is wrong".

Dow appears to be unaffected by the scepticism of scientists in Europe and the US. Bumb claims that "results which depart from traditional and commonlyheld beliefs routinely provoke scepticism'. And he remains confident in Dow's results and the company's conclusions.

Bumb and Rappe will have a further opportunity to put their respective cases in November, when both will present evidence in hearings organised by the US Environmental Protection Agency. The EPA is to consider its ban on the herbicide $2,4,5-\mathrm{T}$, which it has recently extended, from a restriction to forestry only, to a total ban covering all known uses of the herbicide in the US. The danger of 2,4,5-T lies in its contamination with small amounts of the dioxin 2,3,7,8-TCDD, one of the subjects of contention in the Dow report.

\title{
Israeli universities face financial crisis
}

ISRAEL'S seven institutions of higher learning have successfully resisted a recent attempt by the Knesset's Finance Committee to cut $£ 8$ million from their budgets.

A threat to double tuition fees or even close down campuses was enough to spur Prime Minister Menahem Begin to intervene. He successfully asked the committee to reverse its decision.

University officials are naturally relieved, but they are still fearful of future developments. Their mood was expressed by a top academic administrator who said that they "had won the battle and yet might go on to lose the war".

This is because the Knesset members who reluctantly agreed to restore the $£ 8$ million and many other influential Israelis apparently believe that the universities and academic research centres are characterised by luxury and waste, which means that they can more readily absorb budget cuts than can other institutions supported by public funds. And such cuts are inevitable if the rampaging, nearly three-digit inflation now plaguing Israel is to be brought under control.

The institutions of higher learning certainly helped to create their image in what Weizmann Institute President Michael Sela some years ago called "the Herodian era of construction", when universities, egged on by donors anxious to have their names associated with imposing edifices, seemed intent on surpassing one another in square metres of marble and concrete.

Yet there are also other, perhaps more significant factors at work. To some extent, as in the West generally, science and scientific institutions are held responsible in Israel for almost all the ills of modern society. In addition, parliamentarians concerned about the problems of the underprivileged and poorly educated sections of Israeli society are ready to divert scarce funds from universities and research centres to nursery schools, primary schools and secondary schools.

In any case, even before their latest tangle with the Knesset's Finance Committee, local institutions of higher learning were already suffering from a severe decline in government support. In the period between 1972 and 1978, when the national budget grew in real terms by $30 \%$, funds allocated to higher education declined in real terms by $20 \%$.

Making things even more difficult for the institutions is the erratic manner in which government allocations are dispensed. Money does not come in regularly week by week or month by month; instead most of it tends to arrive towards the end of the fiscal year.

Yet the universities are prohibited by law from withholding wages, and if they don't pay for their supplies, the supplies stop. This forces them to take high interest loans in order to bridge the gap between current expenditure and eventual government grants. University spokesmen claim that economy measures have already gone past the stage where fat was being trimmed and now are impairing their ability to operate properly. According to Tel Aviv University President Haim Ben-Shahar, "libraries and laboratories are no longer up to date. Journals containing important current research developments are sometimes impossible to acquire. Our scientists are forced to work with obsolete equipment, which, of course, puts them at a disadvantage in comparison to their colleagues abroad".

A research chemist at another institution told of a case in point. For some years, he said, the people in his department have been seeking funds to purchase a gas chromatograph mass spectrometer. At first they could go on with experiments by constantly tinkering with their old mass spectrometer, purchased in the early 1960s. But now some lines of research have had to be dropped as it is impossible to obtain relevant and significant results without the newer instrument.

Financial problems have severely limited the hiring of new staff, leaving institutions of higher learning with a disproportionate number of aging, tenured men and women. This news about job prospects has reached university students, and it undoubtedly has something to do with declining enrolments in the natural sciences.

Chemistry faculties are particularly hard hit, with registration down by anywhere from a quarter to three-quarters and some institutions now boasting more teaching staff than students. The same applies to a lesser extent to other science faculties. Students are now choosing short courses promising good employment prospects and the possibility of high financial gain. 